Neuroscience, Children's National Medical Center, 111 Michigan Ave NW, Washington, DC 20010. E-mail: wgaillar@,cnmc.org).

COMMENT. Imaging is most useful for children with localization-related or remote symptomatic generalized epilepsy. MRI abnormalities are more frequent in infants with seizures than in older children because of presentation of cortical malformations. The authors advise that children younger than 2 years require special MRI sequences because immature myelination may obscure the diagnosis of cortical dysplasia. If the MRI is interpreted as normal and seizures persist, repeat imaging at 6-month intervals is advised, when myelination is more mature and dysplasias can be distinguished. Gadolinium contrast is reserved for suspected tumor, vascular malformation, inflammation, and infectious disorders.

\title{
LONG-TERM OUTCOME OF JUVENILE MYOCLONIC EPILEPSY
}

All patients developing juvenile myoclonic epilepsy (JME) by 16 years of age in Nova Scotia between 1977 and 1985 were contacted in 2006-2008 to determine long-term seizure and social outcome, in a study at Dalhousie University, Halifax, Canada. Of 24 patients (17 women) with JME, 23 were contacted at a mean age of $36+/-4.8$ years. Age at first seizure was $10.4+/-4.3$ years. At 25-year follow-up, 11 (48\%) had discontinued AED treatment: 6 were seizure-free (without AEDs) for 5-23 years, 3 had only myoclonic seizures, and 2 had rare seizures. Of those with continued seizures, $8(36 \%)$ had episodes of convulsive status epilepticus, and 3 had intractable epilepsy. Seventy percent enjoyed satisfactory health, work, friendships, and social life, $87 \%$ graduated high school, and $69 \%$ were employed. Nine were taking antidepressants. Ten women had been pregnant and 4 men were fathers. Eleven pregnancies $(80 \%)$ were unplanned, and at least 1 unfavorable social outcome was noted in 76\%. (Camfield CS, Camfield PR. Juvenile myoclonic epilepsy 25 years after seizure onset: A population-based study. Neurology Sept 29, 2009;73:10411045). (Response and reprints: Dr Carol S Camfield, IWK Health Centre, PO Box 9700, 5850 University Ave, Halifax, Nova Scotia, Canada B3K 6R8. E-mail: camfield@,dal.ca).

COMMENT. One-third patients with JME at 25-year follow-up have seizures well controlled and AED discontinued, in contrast to the generally poor seizure outcome in previous reports. Three-quarters have experienced at least one major unfavorable social event, but $70 \%$ report satisfaction with their social life.

\section{VASCULAR DISORDERS}

\section{CEREBRAL VENOUS SINUS THROMBOSIS CASE SERIES}

Presenting features, co-morbid conditions, treatment, and outcome of cerebral venous sinus thrombosis (CVST) in a consecutive series of children are reported from Department of Paediatric Neurology, Bristol Royal Hospital for Children, UK. Twenty-one children (10 male) were diagnosed with CVST (using electronic databases and international codes) and treated in a single pediatric neurology center over a period of 8.25 years. Ages ranged from 1.4 to 16.9 years (median 7.1 years); neonates were not included. Presenting symptoms in 